\title{
Peripuberty stress leads to abnormal aggression, altered amygdala and orbitofrontal reactivity and increased prefrontal MAOA gene expression
}

\author{
C Márquez ${ }^{1}$, GL Poirier ${ }^{1}$, MI Cordero ${ }^{1}$, MH Larsen ${ }^{1}$, A Groner $^{2}$, J Marquis ${ }^{2}$, PJ Magistretti $^{3}$, D Trono ${ }^{2}$ and C Sandi ${ }^{1}$
}

\begin{abstract}
Although adverse early life experiences have been found to increase lifetime risk to develop violent behaviors, the neurobiological mechanisms underlying these long-term effects remain unclear. We present a novel animal model for pathological aggression induced by peripubertal exposure to stress with face, construct and predictive validity. We show that male rats submitted to fear-induction experiences during the peripubertal period exhibit high and sustained rates of increased aggression at adulthood, even against unthreatening individuals, and increased testosterone/corticosterone ratio. They also exhibit hyperactivity in the amygdala under both basal conditions (evaluated by 2-deoxy-glucose autoradiography) and after a resident-intruder (RI) test (evaluated by c-Fos immunohistochemistry), and hypoactivation of the medial orbitofrontal (MO) cortex after the social challenge. Alterations in the connectivity between the orbitofrontal cortex and the amygdala were linked to the aggressive phenotype. Increased and sustained expression levels of the monoamine oxidase $A(M A O A)$ gene were found in the prefrontal cortex but not in the amygdala of peripubertally stressed animals. They were accompanied by increased activatory acetylation of histone $\mathrm{H} 3$, but not $\mathrm{H} 4$, at the promoter of the MAOA gene. Treatment with an MAOA inhibitor during adulthood reversed the peripuberty stress-induced antisocial behaviors. Beyond the characterization and validation of the model, we present novel data highlighting changes in the serotonergic system in the prefrontal cortex-and pointing at epigenetic control of the MAOA gene-in the establishment of the link between peripubertal stress and later pathological aggression. Our data emphasize the impact of biological factors triggered by peripubertal adverse experiences on the emergence of violent behaviors. Translational Psychiatry (2013) 3, e216; doi:10.1038/tp.2012.144; published online 15 January 2013
\end{abstract}

\section{Introduction}

Epidemiological studies have shown that adverse experiences during childhood, particularly fear and maltreatment, enhance the risk of developing violent behaviors. ${ }^{1}$ Deviation from the normal development of social, emotional and cognitive abilities has been proposed to mediate the association between early adversity and aggression later in life; ${ }^{2}$ however, the associated neurobiological mechanisms remain unclear.

There has been increasing evidence for the associations linking early adversity to the serotonin (5-HT) system and pathological impulsive aggression in adulthood both in humans and animals. ${ }^{3-7}$ Early studies established a connection between aggressive behavior and deficiency in the expression or activity of the monoamine oxidase $A(M A O A)$ gene, which encodes a catabolic enzyme that degrades biogenic amines including $5-\mathrm{HT}$. $^{8,9}$ Subsequently, common polymorphisms in the genes of the serotonergic circuitrynotably the $5-\mathrm{HT}$ transporter (5HTT) and MAOA (with abundant evidence for the latter)-were found to increase the risk of antisocial and aggressive behaviors following childhood adversity ${ }^{10-14}$ (but see Kim-Cohen et al. ${ }^{15}$ ). Interestingly, the MAOA allelic variant that mediates the effect of early life maltreatment on the development of antisocial behavior $^{10}$ was independently associated with increased reactivity in the amygdala and reduced activity in the regulatory prefrontal regions (orbitofrontal and anterior cingulate cortices) in response to an emotional challenge. ${ }^{16}$ Similarly, the 5HTT allelic variant that reportedly links early adversity to the development of aggression ${ }^{12}$ was also associated with increased amygdala activity and reduced cingulate cortex activation under emotional arousal. ${ }^{17}$ Changes in these corticolimbic networks have been linked to aggressive behavior in lesion and stimulation studies (for a review, see Coccaro et al. ${ }^{18}$ ) and linked to a dysfunction of the amygdala-orbitofrontal cortex response to social threats in functional neuroimaging studies in individuals with impulsive aggression. ${ }^{19}$

Recent work has shown that extreme levels of early life stress can lead to increased aggression independently of these genetic variations. ${ }^{12,14}$ These observations suggest that

\footnotetext{
${ }^{1}$ Laboratory of Behavioral Genetics, Brain Mind Institute, School of Life Sciences, Ecole Polytechnique Federale de Lausanne (EPFL), Lausanne, Switzerland; ${ }^{2}$ Laboratory of Virology and Genetics, Global Health Institute, School of Life Sciences, Ecole Polytechnique Federale de Lausanne (EPFL), Lausanne, Switzerland and ${ }^{3}$ Laboratory of Neuroenergetics and Cellular Dynamics, Brain Mind Institute, School of Life Sciences, Ecole Polytechnique Federale de Lausanne (EPFL), Lausanne, Switzerland

Correspondence: Professor C Sandi, Laboratory of Behavioral Genetics, Brain Mind Institute, School of Life Sciences, Ecole Polytechnique Federale de Lausanne (EPFL), EPFL-SV-BMI, Station 19, Lausanne 1015, Switzerland.
}

E-mail: carmen.sandi@epfl.ch

Keywords: abnormal aggression; amygdala; early life; $\mathrm{H} 3$ acetylation; MAOA; prefrontal cortex

Received 28 July 2012; revised 23 October 2012; accepted 10 November 2012 
high levels of stress experienced during critical developmental periods can alter the expression of serotonergic genes and affect the functioning of associated brain areas and their connectivity. ${ }^{20,21}$ In monkeys, low 5HTT expression in peripheral blood mononuclear cells was found to be a predictor of behavioral disinhibition following early life stress independent of a polymorphism in the promoter of the 5HTT gene. ${ }^{22} \mathrm{~A}$ study investigating hypothalamic 5-HT expression in a rat model of enhanced intermale aggression induced by maternal separation provided evidence for the serotonergic system to exhibit long-lasting stress effects. ${ }^{23}$ However, whether early life stress can directly affect the activity of serotonergic pathways in higher brain areas and circuits implicated in human aggression (for example, the amygdala and the prefrontal cortex (PFC)) remains unknown. Changes in epigenetic markers in the 5-HT gene-increased methylation of its promoter region-have been observed in lymphoblasts of women submitted to childhood abuse and proposed to mediate the impact of child maltreatment on antisocial behavior. ${ }^{24}$ However, there is currently no available evidence that early life experience can have long-lasting changes in epigenetic markers associated to serotonergic neural mechanisms.

To address these questions, we utilized a rat protocol developed in our laboratory, ${ }^{25}$ and based on the exposure to stressful experiences during the peripubertal period (from postnatal days P28 to P42), to investigate intermale aggressive behaviors in adult rats. We selected the peripubertal period (instead of manipulating stress before weaning as many other studies in the literature do) to tackle specifically this important developmental phase when significant maturation processes occur in particular brain regions important for emotion and cognition, resembling the period spanning childhood and puberty in humans. ${ }^{26,27}$ At adulthood, we investigated the brain activity of peripubertally stressed rats along with brain-region-specific changes in the expression of the MAOA and 5HTT genes, and assessed potential changes in histone acetylation associated with the observed increased expression in these genes. A pharmacological approach based on the neurobiological findings was also applied to assess the therapeutic implications for reversibility of the aggressive phenotype.

\section{Materials and methods}

Animals. The experimental subjects were the offspring of Wistar Han rats (Charles River Laboratories, L'Arbresle, France), bred in our animal house. Male rats from different litters were mixed throughout the different home cages by placing equivalent numbers of animals from each litter into the stress or control group and by avoiding having siblings in the same home cage. They were housed 2-3 animals per standard plastic cage on a $12 \mathrm{~h}$ light-dark cycle (lights on at $0700 \mathrm{~h}$ ). Food and water were available ad libitum. All procedures were conducted in conformity with the Swiss National Institutional Guidelines on Animal Experimentation and approved by a license from the Swiss Cantonal Veterinary Office Committee for Animal Experimentation.

Peripubertal stress protocol. This protocol is based on exposure to fear-induction procedures. Following exposure to an open field for 5 min on day P28, the stress protocol consisted on the presentation of two different fear-inducing stressors (each one lasting $25 \mathrm{~min}$ ): (1) the synthetic fox odor trimethylthiazoline $(9 \mu \mathrm{l})$ (Phero Tech Inc., Delta, BC, Canada), which was administered in a plastic box $(38 \times$ $27.5 \times 31 \mathrm{~cm})$ through a small cloth. The box was placed under a bright light (210-250 Ix); and (2) exposure to an elevated platform $(12 \times 12 \mathrm{~cm}$ elevated $95 \mathrm{~cm}$ from the ground) under direct bright light (470-500 lx). Following each stress session, the animals were returned to their home cages where, during the first $15 \mathrm{~min}$, a transparent Plexiglas wall with holes separated each animal.

The stressors were applied during the peripuberty period (a total of 7 days across the P28-P42 period, that is, on P28-30, P34, P36, P40 and P42) during the light phase following an unpredictable schedule. The order and timing of the stressors were changed on different days. On some stress days, only one stressor was presented, while on other days, the two stressors were given consecutively (for details on the specific protocol, see Supplementary Figure S1a and Supplementary Videos S1and S2). The control animals were handled on the days that their experimental counterparts were exposed to stress. In one experiment, the same stress procedure instead of being applied during the peripuberty period, it was applied at adulthood (see details in Supplementary Figure S1b).

Assessment of endocrine, behavioral and neurobiological consequences of peripubertal stress. Different experiments were carried out in which the behavioral effects of peripubertal stress at adulthood and/or neurobiological end points were examined (Supplementary Figure S2). At the behavioral level, our main focus was the evaluation of aggressive behaviors through different $\mathrm{RI}$ tests that varied depending on the nature of the intruder (that is, whether anesthetized, or similar, smaller or larger than the resident animal). Evaluation of social behaviors was complemented with the sociability test. Other behavioral domains evaluated were anxiety-like (through the elevated plus maze (EPM)) and depression-like (through the forced swim and sucrose consumption tests) behaviors.

Characterization of stress hormones responsivity and puberty onset after peripubertal stress. Control $(n=45)$ and peripubertally stressed animals $(n=43)$ were used to characterize the effects of the peripubertal stress protocol (Supplementary Figure S2, cohorts 1,6 and 7). At specific days during peripuberty (P36, P37, P40, P43 and P50), an experimenter blind to the stress condition evaluated the moment of puberty onset by direct observation of prepuce separation. Moreover, corticosterone levels were measured in a subset of stressed animals $(n=35)$ on the first (P28) and last days (P42) of the stress protocol. Blood samples were collected using the tail-nick protocol under basal conditions, immediately following the termination of the elevated platform stress and 30 and $60 \mathrm{~min}$ after the elevated platform stress.

Effects of peripubertal stress on aggressive behaviors and hormonal reactivity. Different sets of control and 
peripubertally stressed rats were tested for different types of aggressive behavior at adulthood (3 months old):

- A cohort of adult control $(n=15)$ and peripubertally stressed animals $(n=16)$ (Supplementary Figure S2, cohort 6) was used to evaluate the aggressive behaviors against a male conspecific in a conventional $\mathrm{RI}$ test as described previously ${ }^{23}$ (that is, after 10 days of cohabitation with a female, including on the night of the test, the male's interaction with a $5 \%$ lighter intruder was tested; see Behavioral tests description for further details). Corticosterone and testosterone responses after the RI test were measured. Blood samples were obtained by the tail-nick procedure immediately and $45 \mathrm{~min}$ after the RI test and by decapitation $3 \mathrm{~h}$ after the end of the RI test. Plasma hormonal levels were measured by the enzymatic immunoassay kit as described below, and the area under the curve for each hormone and the ratio between the two hormones were calculated.

- Another set of animals ( $n=6$ per group) was used to measure the targets of the attacks (vulnerable vs non-vulnerable targets) in a conventional $\mathrm{Rl}$ test (Supplementary Figure S2, cohort 3).

- Another set of animals ( $n=10$ per group) was used to perform a more careful characterization of the aggressive profile of animals (Supplementary Figure S2, cohort 4). Different types of $\mathrm{Rl}$ tests were performed, including experimental conditions in which the intruder was an anesthetized animal similar in body weight to the resident or in which the intruder was 5 or $50 \%$ lighter or $25 \%$ larger than the resident. Each test was separated by at least 1 week. The intruders were all socially experienced (housed 3 animals per cage in their home cages), but naïve to the $\mathrm{RI}$ test. Thus, each intruder was used only once and was not re-used for other aggressive encounters (to avoid winner or loser effects).

Effects of peripubertal stress on depression-like behaviors. Control and peripubertally stressed animals ( $n=9$ per group; Supplementary Figure S2, cohort 1) were tested for depression-like behaviors using the following tests in the specified order during adulthood (3 months old): sucrose consumption, ${ }^{28}$ sociability, ${ }^{29,30}$ and forced swimming tests ${ }^{31}$ (see Behavioral tests description for further details). There were at least 3 days between each behavioral test.

Effects of peripubertal stress on anxiety-like levels. The anxiety-like behavior of control and peripubertally stressed animals was tested using the EPM ${ }^{32}$ during adulthood (3 months old; $n=30$ per group; Supplementary Figure S2, cohort 2).

Effects of peripubertal stress on basal brain energy metabolism. At 1 week after the behavioral testing on the elevated-plus maze, eight animals per group were used to evaluate the brain glucose metabolism under basal conditions (Supplementary Figure S2, cohort 2). These animals were injected intraperitoneally with $\left[1-{ }^{14} \mathrm{C}\right] 2$-deoxy-D-glucose $(165 \mu \mathrm{Ci} / \mathrm{kg}$; Hartmann Analytic, Braunschweig, Germany)
45 min before being killed. The brains were removed and quickly frozen in isopentane precooled with dry ice. The frozen brains were stored at $-80^{\circ} \mathrm{C}$ until processing for the 2-deoxy-glucose procedure imaging technique (see Supplementary Methods for further details).

c-Fos activation after an aggressive encounter. At 3 months old, control and peripubertally stressed animals ( $n=8$ and 9 , respectively; Supplementary Figure S2, cohort 5) were submitted to a conventional RI test protocol. At 90 min after the behavioral testing, the animals were anesthetized with isoflurane and perfused via the ascending aorta with ice-cold $0.9 \%$ saline, followed by $4 \%$ paraformaldehyde in phosphate-buffered saline $(\mathrm{pH}=7.5)$. Their brains were subsequently removed, postfixed and processed for c-Fos immunohistochemistry (see Supplementary Methods for further details).

Gene expression and chromatin modification changes after peripubertal stress. Control and peripubertally stressed animals were killed during adulthood ( 3 months old) either under basal conditions or $3 \mathrm{~h}$ after the end of the $\mathrm{RI}$ test. Thus, the experiment involved four experimental groups ( $n=9-10$ per group; Supplementary Figure S2, cohort 6). After decapitation, the fresh brains were quickly removed, and the areas of interest were quickly dissected on dry ice and placed into liquid nitrogen in RNase-free cryotubes. The samples were stored at $-80^{\circ} \mathrm{C}$ until further processing for RNA extraction or chromatin immunoprecipitation (ChIP) protocols (see Supplementary Methods for further details).

Effects of pharmacological treatment with the MAOA inhibitor clorgyline on aggressive and social behaviors. At 3 months old, control and peripubertally stressed animals $(n=16$ and 18, respectively; Supplementary Figure S2, cohort 7) were assigned either to vehicle or a low, chronic dose of the irreversible and selective MAOA inhibitor clorgyline (Sigma, Basel, Switzerland; subcutaneously, $1 \mathrm{mg} / \mathrm{kg}$ per day). The animals were injected with drug or vehicle (physiological saline) every morning for 3 weeks and then tested to analyze their behaviors in the sociability and RI tests. The sociability test was conducted on the 21st day of clorgyline treatment immediately before the last injection (approximately $24 \mathrm{~h}$ after the injection on the previous day). The RI test was performed during the dark cycle of the 23rd day, approximately 55-60 h after the last injection.

Specificity of the peripubertal period as a critical moment for the long-term effects of stress. To test if the behavioral phenotype observed in the peripubertally stressed animals was due to the time period when it is applied (that is, peripuberty), an additional experiment was performed in which the same stress protocol was given to adult animals (3 months old). A total of 24 male Wistar rats ( $n=12$ per group) were used (Supplementary Figure S2, cohort 8). The behavioral tests were performed 2 months after stress application (that is, to allow for the same delay period as in the peripubertal stress studies). Thus, 5-month-old control and stressed animals were evaluated in the sucrose preference test, the EPM and the RI test. 


\section{Behavioral tests}

$R$ I test. Rats underwent the RI tests at 3-4 months of age. The RI protocol was adapted from Veenema et al. ${ }^{23}$ Briefly, each rat was housed in an experimental cage $(40 \times 29 \times 20$ $\mathrm{cm}^{3}$ ) with a female Wistar rat for 10 days. The female was removed from the resident's home cage $30 \mathrm{~min}$ before each test and was returned after the test. The RI tests were conducted during the beginning of the dark cycle (between 1930 and 2130 hours). During the standard RI test, the resident control or peripubertally stressed male was exposed in its home cage to a slightly smaller $(5 \%$ of body weight difference), unfamiliar male Wistar rat for $30 \mathrm{~min}$. The rats were exposed to a single RI test, and the intruders were used only once. The tests were videotaped, and the behavioral scoring was conducted by an experimenter blind to the treatment conditions and assisted by a computer program (The Observer 5.0.25, 2003; Noldus Information Technology, Wageninge, The Netherlands). The following parameters related to intermale aggression were scored for the intruders and the residents: attack latency time, number of attacks, lateral threat, clinch, offensive upright and keep down. The percentage of the time spent performing the latter four behavioral parameters was summarized as the total aggressive behavior. To determine the aggressive behavior of each pair of animals, the aggressive behavior ratio was calculated as follows: (aggressive behavior of the resident $\times 100$ / (resident + intruder aggressive behaviors)). ${ }^{33}$ In another set of animals, a detailed video analysis (frame by frame when necessary) was performed to identify the target of the attacks. Hard bites were scored as targeted toward vulnerable (head, throat and belly of their opponents) or nonvulnerable parts of the opponent. The percentage of the hard bites targeted toward vulnerable parts was calculated. Furthermore, social behaviors (consisting of general investigation or anogenital sniffing of the opponent), grooming and the submissive behaviors of the intruders were also scored.

To further characterize the aggressive profile of the animals, different variants of the conventional RI test were performed, as follows:

$R I$ test with an anesthetized intruder. In this experiment, the intruder placed into the home cage of either the control or the peripubertally stressed rat was an anesthetized male with a body weight similar to that of the resident. The interaction (30 min) was videotaped, and the behavioral scoring was conducted with the assistance of a computer program (The Observer 5.0.25, 2003; Noldus IT). The following behaviors of the resident animal against the intruder were scored: burying, bites, jumps and displacements (that is, aggressive behaviors) and grooming.

RI test with a small intruder. A small, naïve intruder of $50 \%$ of the body weight of the resident was introduced into the control or peripubertally stressed animal's home cage for $15 \mathrm{~min}$. The following parameters related to intermale aggression were scored blindly for the intruders and the residents using a computer program (see above): attack latency time, number of attacks, lateral threat, clinch, offensive upright and keep down. As the intruders rarely displayed aggressive behaviors, calculating the ratio of the aggressive behaviors between the resident and intruder did not provide the best information concerning this type of encounter. Furthermore, social behaviors (consisting of investigating the opponent and anogenital sniffing), grooming and the submissive behaviors of the intruders were also scored.

$R$ I test with a large intruder. A larger intruder of $125 \%$ the body weight of the resident was introduced into the control or peripubertally stressed animal's home cage for $30 \mathrm{~min}$. The following parameters related to intermale aggression were scored for the intruders and the residents: attack latency time, number of attacks, lateral threat, clinch, offensive upright and keep down. Furthermore, social behaviors (consisting of investigating the opponent and anogenital sniffing), grooming and the submissive behavior of the intruders were also scored.

Sociability test. The sociability test was adapted from the protocol described by Crawley to investigate the sociability of male mice. ${ }^{29}$ Briefly, the test was conducted in a rectangular, three-chambered box (a center chamber of $20 \times 35 \times 35 \mathrm{~cm}$ and left and right compartments of $30 \times 35 \times 35 \mathrm{~cm}$ ) fabricated from gray opaque polycarbonate. The dividing walls had retractable doorways allowing access to each chamber. The left and right compartments contained a central Plexiglas cylinder $(15 \mathrm{~cm}$ in diameter) that was transparent with small holes where either a social (unfamiliar juvenile rat approximately 34 days old) or a non-social stimulus (yellow plastic bottle) was placed. The cylinder permitted visual, tactile, auditory and olfactory communication. This allowed evaluating the social approach tendencies while avoiding potential confounds resulting from aggressive or sexual interactions. ${ }^{29}$ The juvenile rats were first habituated to the three-chambered apparatus by placing them individually in the box within the Plexiglas cylinder for $10 \mathrm{~min}$ during the 3 consecutive days preceding the social test.

On the testing day, the test rat was first placed into the middle chamber and allowed to explore for $5 \mathrm{~min}$. The doorways into the two side chambers were closed during this habituation phase. After the habituation period, the unfamiliar juvenile was placed into one of the side chambers, and the object was placed in the other side chamber. The locations of the juvenile and the object in the left vs right sides of the chamber were counterbalanced. Next, both doors to the side chambers were carefully removed, and the rat was allowed to explore the entire apparatus for a 10-min session. The session was video-recorded, and the time spent sniffing each cylinder was manually scored by an experimenter blind to the treatments to evaluate the level of preference for the unfamiliar juvenile compared with the object (exploration time ratio $=$ time exploring the juvenile/time exploring the object). The entire apparatus was cleaned with $5 \%$ acetic acid solution and dried thoroughly between each test.

Elevated plus maze. Anxiety-like levels were evaluated using the EPM test. ${ }^{32}$ Briefly, the test consists of two opposing open arms $(50 \times 10 \mathrm{~cm})$ perpendicular to two enclosed arms $(50 \times 10 \times 50 \mathrm{~cm})$ that extend from a central platform $(10 \times 10 \mathrm{~cm})$ elevated $65 \mathrm{~cm}$ above the floor. The rats were placed individually on the central platform facing a closed arm and allowed to explore the maze for $5 \mathrm{~min}$. Their behavior was monitored using a video camera and analyzed with a computerized tracking system (Ethovision 3.1.16; Noldus IT). The time spent in the open and closed arms, the latency to enter the open arm, the distance traveled and the 
transitions between the different arms were recorded. The entire apparatus was cleaned with $5 \%$ acetic acid solution and dried thoroughly between each animal.

Forced swimming test. The rats were submitted to a forced swimming test to evaluate depression-like behaviors. ${ }^{31,34}$ Briefly, the animals were individually placed in a plastic beaker ( $25 \mathrm{~cm}$ diameter, $46 \mathrm{~cm}$ deep) containing $30 \mathrm{~cm}$ of water $\left(25^{\circ} \mathrm{C}\right)$ for $15 \mathrm{~min}$. A second session was performed $24 \mathrm{~h}$ later for 5 min. ${ }^{35}$ Their behaviors were recorded with a video camera, and the time spent immobile (making only those movements necessary to keep the snout above the water), swimming, climbing or diving was manually quantified with the aid of a computer program (The Observer 5.0.25, 2003; Noldus IT) by an experimenter who was blind to the experimental condition.

Sucrose consumption. Sucrose consumption was measured to evaluate anhedonic symptoms in the experimental animals. The relative preference for a sucrose-sweetened solution (vs water) provides a simple measure related to the anhedonia seen in depressive patients. ${ }^{28}$ Sucrose intake (1\% sucrose solution) was measured at basal conditions during adulthood. Two preweighted bottles, containing 0\% (tap water) or $1 \%$ sucrose solution, were placed in each cage. The animals were allowed to freely drink from the two bottles during an overnight window. The rats were not deprived of food or water to avoid any stress related to these procedures. Consumption was measured by comparing the bottle weight before and after the overnight window. The intake was expressed in relation to each animal's body weight $(\mathrm{g} / 100 \mathrm{~g}$ of body weight).

Plasma corticosterone and testosterone measurements. Blood samples were obtained either by the tail-nick procedure or decapitation depending on the experiment. The tailnick procedure allows for the collection of blood samples at different time points from the same animal, ${ }^{36}$ which enables the study of hormonal dynamics. In the tail-nick procedure, blood samples (up to $100 \mu \mathrm{l}$ for peripubertal and $250 \mu \mathrm{l}$ for adult animals) were taken within 2 min from starting the procedure and collected into ice-cold heparinized capillary tubes (Sarsted, Sevelen, Switzerland). The plasma obtained after centrifugation was stored at $-20^{\circ} \mathrm{C}$ until analysis. To obtain the decapitation blood samples, the animals were euthanized in an adjacent room within $30 \mathrm{~s}$ of removal from the holding room. The trunk blood was collected in tubs containing heparin and centrifuged at $4{ }^{\circ} \mathrm{C}$, and the serum was frozen at $-20^{\circ} \mathrm{C}$ until the analysis.

Plasma corticosterone and testosterone levels were measured using an enzymatic immunoassay kit (Correlate-EIA from Assay Designs Inc., Ann Arbor, MI, USA) according to the supplier's recommendations. The area under the curve of the corticosterone and testosterone levels was calculated using GraphPad Prism (version 4), which computes the area under the curve using the trapezoid rule.

Imaging brain activity and modeling dynamic brain interactions. Potential differences in brain activity between control and peripubertally stressed animals were evaluated at adulthood both under basal conditions (using the $\left[{ }^{14} \mathrm{C}\right] 2$ deoxy-glucose procedure) and after the standard $\mathrm{Rl}$ test (using c-Fos immunohistochemistry, $90 \mathrm{~min}$ after the end of the test) (see Supplementary Methods for further details). We used these two complementary techniques at different time points to obtain a picture of brain activity while avoiding injecting animals before the social encounter. Dynamic brain interactions after the RI test were modeled through structural equation modeling that was applied with maximum-likelihood estimation to evaluate the effective network connectivity ${ }^{37-39}$ (see Supplementary Methods).

mRNA quantification and ChIP. Potential changes in the expression of candidate genes were explored (see Supplementary Table S1 for primer sequences). For this purpose, mRNA was assessed by quantitative real-time polymerase chain reaction and significant changes in gene expression followed up by the assessment of histone acetylation by ChIP procedures, as described previously ${ }^{40}$ (see Supplementary Methods).

Statistics. The SPSS 13.0 (SPSS, Chicago, IL, USA) statistical package was used for the statistical analyses. The normality and homogeneity of variance of the data were tested, and the adjusted statistics were used as required. Independent-samples $t$-tests were performed to compare differences between control and peripuberty stress groups. Analysis of variance (ANOVA) of repeated measures with stress as between-subject factor and time as within-subject factor was used to study the evolution over time of aggressive and submissive behaviors in the RI test in control and peripuberty stress groups. ANOVAs of repeated measures were performed in the analysis of brain activity studies (2-deoxy-glucose procedure and c-Fos), with stress as between-subject group and different subregions of candidate brain areas as within-subject factor. Post hoc comparisons were used when required. Dynamic brain interactions after the $\mathrm{RI}$ test were modeled through structural equation modeling (see Supplementary Methods). Peripuberty stress effects on gene expression and epigenetic regulation were assessed with two-way ANOVA with stress (control/peripuberty stress) and moment of sampling (basal/ after RI test) as independent factors. Finally, two-way ANOVAs were performed to study the reversibility of the main behavioral effects of peripuberty stress with the MAOA inhibitor, with stress (control/peripuberty stress) and drug (vehicle/clorgyline) as independent factors. The different statistical analyses used for each experiment are indicated in the figure legends and explained in Supplementary Methods. Statistical significance was set at $P<0.05$.

\section{Results}

Stressful nature of peripubertal exposure to fearful experiences. We first characterized the stressful nature of the peripuberty stress protocol based on exposure to fearinduction experiences (Materials and methods, Supplementary Figure S1 and Supplementary Videos S1 and S2). Stressed animals displayed a robust stress response to our protocol, as indicated by increased 
corticosterone release during the first and the last stress days (Supplementary Figure S3). In addition, exposure to these fear-induction experiences led to a delay on the puberty onset (Supplementary Figure S4).

Long-term behavioral and endocrine consequences of peripubertal stress. We then evaluated the long-term behavioral consequences of exposure to peripuberty stress, with a particular focus on aggressive behaviors. Importantly, peripubertally stressed animals displayed a pattern of pathological aggression during adulthood when exposed to different $\mathrm{Rl}$ tests against a variety of male intruders, including: (i) animals of similar body weights (Figure 1a-d and Supplementary Videos S3 and S4), which were more frequently attacked by peripubertally stressed rats than by controls (Figure 1a and c), particularly in vulnerable body parts (Figure 1d), despite showing high signals of submissive behavior (Figure 1b); (ii) animals that did not pose a real threat (for example, an anesthetized intruder (Figure 1e) or a smaller intruder that was $50 \%$ lighter than the resident (Figure 1f)), indicating a mismatch between provocation and response; and (iii) larger intruders (Figure 1g) that posed a greater threat. The plasma testosterone/corticosterone ratio measured after the $\mathrm{RI}$ test was higher in peripubertally stressed animals than in the controls (Figure $1 \mathrm{~h}$ and Supplementary Figure S5).

We further evaluated whether other behaviors would also be affected by peripubertal stress exposure. In the social domain, peripubertally stressed animals were less motivated than controls to explore a juvenile conspecific when tested in the three-chamber sociability test (Figure 1i). In addition, peripubertally stressed animals showed increased anxietylike (Supplementary Figure S6a-e) and depression-like behaviors (Supplementary Figure S6g and h). Importantly, these behavioral alterations (for example, in the aggression (Figure 1j) and anxiety- and depression-like (Supplementary Figure S6f and i) tests) were not observed when the fearinduction protocol was applied during adulthood (for experimental design, see Supplementary Figure S1b).

\section{Long-term neurobiological consequences of peripuber-} tal stress. To ascertain the neuroanatomical substrates of this peripubertal stress-induced aggressive syndrome, basal brain energy metabolism $\left(\left[{ }^{14} \mathrm{C}\right] 2\right.$-deoxy-glucose autoradiography; Figure $2 \mathrm{a}$ and $\mathrm{b}$ ) and neural activity after the RI test (c-Fos immunoreactivity; Figure 2c and d) were studied. We used these two complementary techniques at different time points to obtain a comprehensive picture of brain activity while avoiding injecting animals before the social encounter. Overall, peripubertally stressed animals showed higher basal energy metabolism in the amygdala (Figure $2 \mathrm{~b}$, upper panel) and marginal increases in the bed nucleus of the stria terminalis and the lateral septum (Figure $2 \mathrm{~b}$, medium panel), but no significant changes were found throughout the PFC (Figure 2c, lower panel). After an aggressive encounter, c-Fos analyses revealed that these animals continued to show hyperactivation of the central and medial amygdala nuclei (Figure 2d, upper panel), but lower expression in the MO cortex and no changes in other PFC subregions (Figure 2d, lower panel) or in other analyzed areas (Figure 2b, middle panel). Effective connectivity analyses
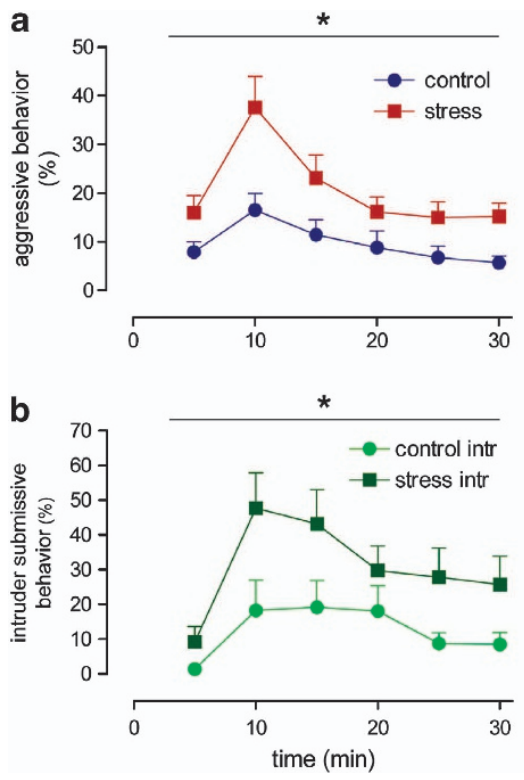
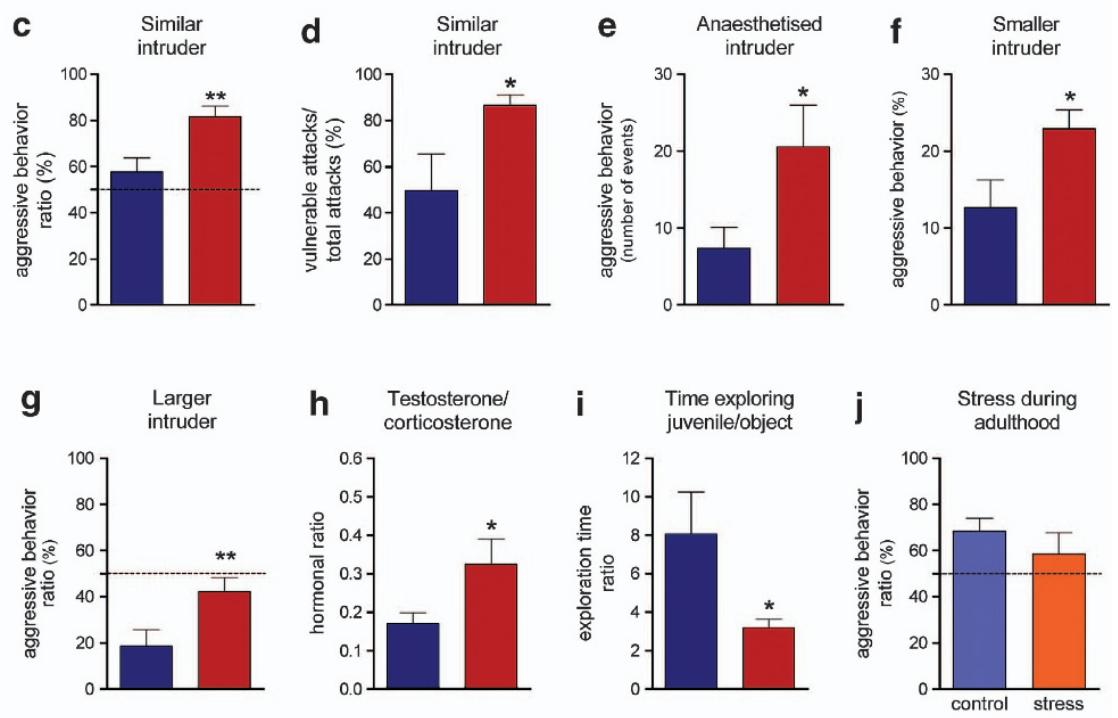

Figure 1 Peripubertal stress-induced abnormal aggressive behaviors in resident-intruder tests performed during adulthood. (a) Aggressive behaviors of resident rats when intruders were similar to the resident rat in body weight (stress effect: $F_{1,29}=9.52, P=0.004 ; n=15-16$ per group). (b) Submissive behaviors of the corresponding intruders (stress effect: $\left.F_{1,29}=5.37, P=0.028\right)$. (c) Corresponding ratio of aggressive behaviors (resident $\times 100 /$ total). (d) Corresponding percentage of hard bites in vulnerable body parts. (e) Aggressive behaviors against an anesthetized intruder. (f) Aggressive behaviors against a young intruder (50\% lighter than the resident). Note that the resident's percentage of time spent in aggressive behaviors is reported, and not the ratio of aggressive behaviors, as of the intruders in this test could not perform significant attacks. (g) Aggressive behavior ratio against a larger intruder. (h) Plasma testosterone/corticosterone ratio after the resident-intruder test. (i) Sociability ratio (time exploring juvenile/time exploring object). (j) Ratio of aggressive behaviors of animals submitted to the same fear-induction protocol during adulthood. Blue: control rats; red: peripubertally threatened rats; orange: rats submitted to stress during adulthood. ${ }^{\star} P<0.05,{ }^{* \star} P<0.005$ vs control. 
Brain activity in basal conditions

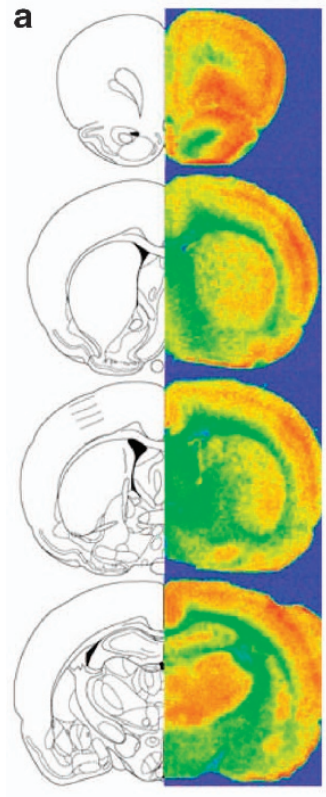

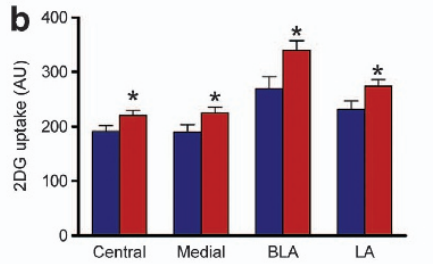
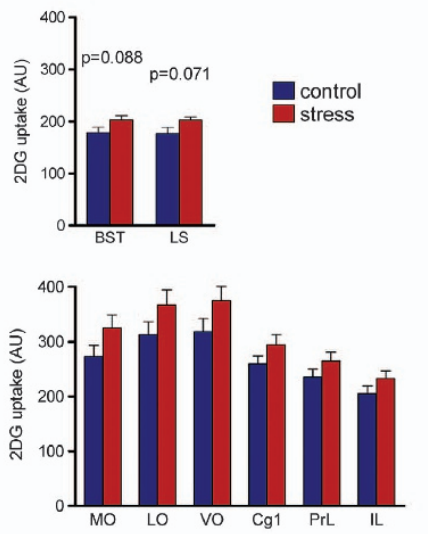

Brain activity after aggression test

C
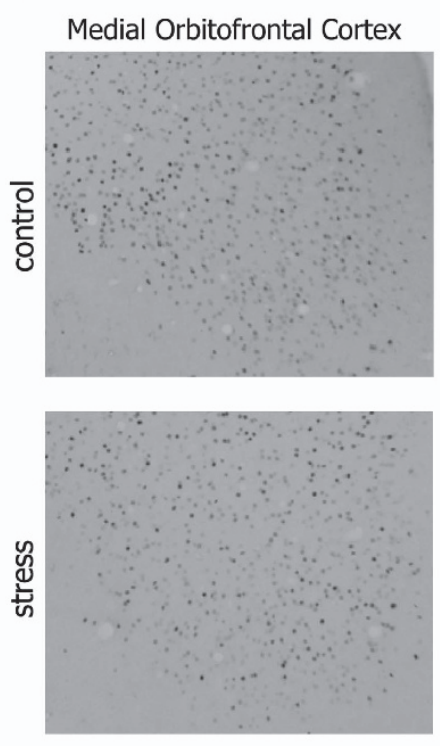
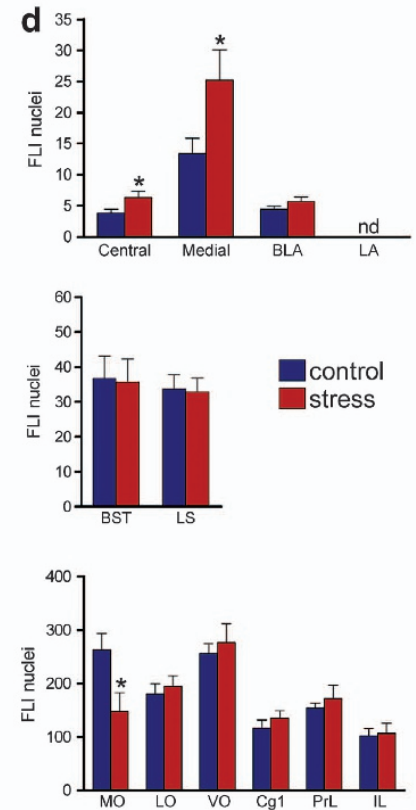

e

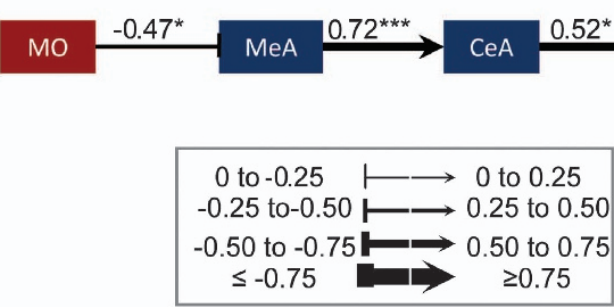

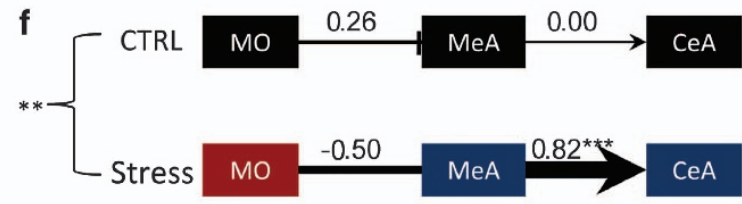

Figure 2 Map of brain activity. (a) Representative $\left[{ }^{14} \mathrm{C}\right] 2$-deoxy-glucose (2-DG) color-coded autoradiographs of coronal rat brain sections indicating the basal brain energy metabolism. (b) Quantification of the 2-DG uptake in different brain regions ( $n=8$ per group). (Upper panel) Amygdaloid nuclei (analysis of variance (ANOVA) of repeated measures revealed a significant stress effect: $F_{1,14}=5.25, P<0.05$; stress $\times$ nuclei interaction: $F_{3,42}=5.31, P<0.005$ ); ${ }^{*} P<0.05$ global stress effect vs control. (Middle panel) Bed nucleus of stria terminalis (BST) and lateral septum (LS). $P$-values from the $t$-test analyses are reported in the graph. (Lower panel) Prefrontal cortical areas. ANOVA of repeated measures reported no significant differences between groups. (c) Representative images of positive Fos-like-immunoreactive (FLI) nuclei (dark staining) after the resident-intruder test. (d) Quantification of FLI nuclei in different brain regions ( $n=8$ per group). (Upper panel) Amygdaloid nuclei (ANOVA of repeated measures: stress effect: $F_{1,14}=4.96, P<0.05$; significant stress $\times$ nuclei interaction: $F_{2,28}=4.19, P<0.05$ ). (Middle panel) BST and LS (NS). (Lower panel) Prefrontal cortical areas (ANOVA of repeated measures: stress $\times$ nuclei interaction: $F_{5,70}=3.57, P<0.006$ ); ${ }^{*} P<0.05$ vs control. (e) Effective connectivity analyses applied to data from the $c$-Fos experiment for all subjects and significant individual paths (good fit of the model; comparative fit index $(\mathrm{CFI})=0.93$; root mean square approximation of variance $($ RMSEA $)=0.14, P>0.87 ; \chi^{2}=3.99$, d.f. $=3, P>0.26$ ). Activities in the medial orbitofrontal $(\mathrm{MO})$ and medial amygdale $(\mathrm{MeA})$ were inversely related and activity in the central amygdala (CeA) was the only predictor of aggressive output. (f) A direct group comparison of effective network connectivity $\left(\chi^{2}=12.4\right.$, d.f. $\left.=3, P<0.006\right)$. Red and blue coloring (e and bottom of f) represent the lowest activation levels in stress or control group, respectively. ${ }^{*} P<0.05,{ }^{\star \star} P<0.01$ and ${ }^{\star \star \star} P<0.001$. Amygdala nuclei: BLA, basolateral; LA, lateral. Prefrontal cortex subregions: LO, lateral orbital; VO, ventral orbital; Cg1, anterior cingulate; PrL, prelimbic; IL, infralimbic; ND, non-detectable; NS, nonsignificant.

revealed alterations in the network dynamics associated with the high aggression provoked by the RI test in peripubertally stressed animals (Figure 2e and f, Supplementary Figure S7 and Supplementary Tables S2 and S3). Unlike controls, peripubertally stressed animals showed a negative coupling between the $\mathrm{MO}$ and the amygdala.

Relevant molecular changes were then investigated in brain regions in which the pattern of activity was found to be affected by peripubertal stress (that is, PFC and amygdala) and in other brain regions implicated in social behaviors and emotional regulation (including septum and raphe nuclei). Quantitative reverse transcription-polymerase chain reaction analyses were used to examine the expression levels of genes related to aggressive behaviors, including MAOA and
$5 H T T$, the variants of which genetically predispose humans for aggressive behaviors. ${ }^{10,12,41}$ Brain samples were collected either under basal conditions or after the $\mathrm{RI}$ test. Peripubertally stressed rats showed increased MAOA and 5HTT mRNA levels in the PFC; however, only the latter was downregulated by social contact (Figure $3 a$ and $b$ ). There were no alterations in any of the other brain regions examined (Supplementary Figure S8). Given the observed increase in MAOA and 5HTT mRNA expression in the PFC, potential epigenetic changes that could be linked to long-term enhancements in gene expression were investigated by determining the acetylation of the relevant histones for these genes. Using ChIP, peripubertally stressed animals were found to exhibit increased relative enrichment of histone 3 


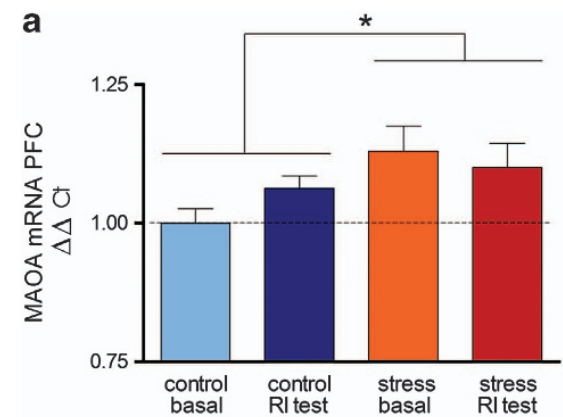

b
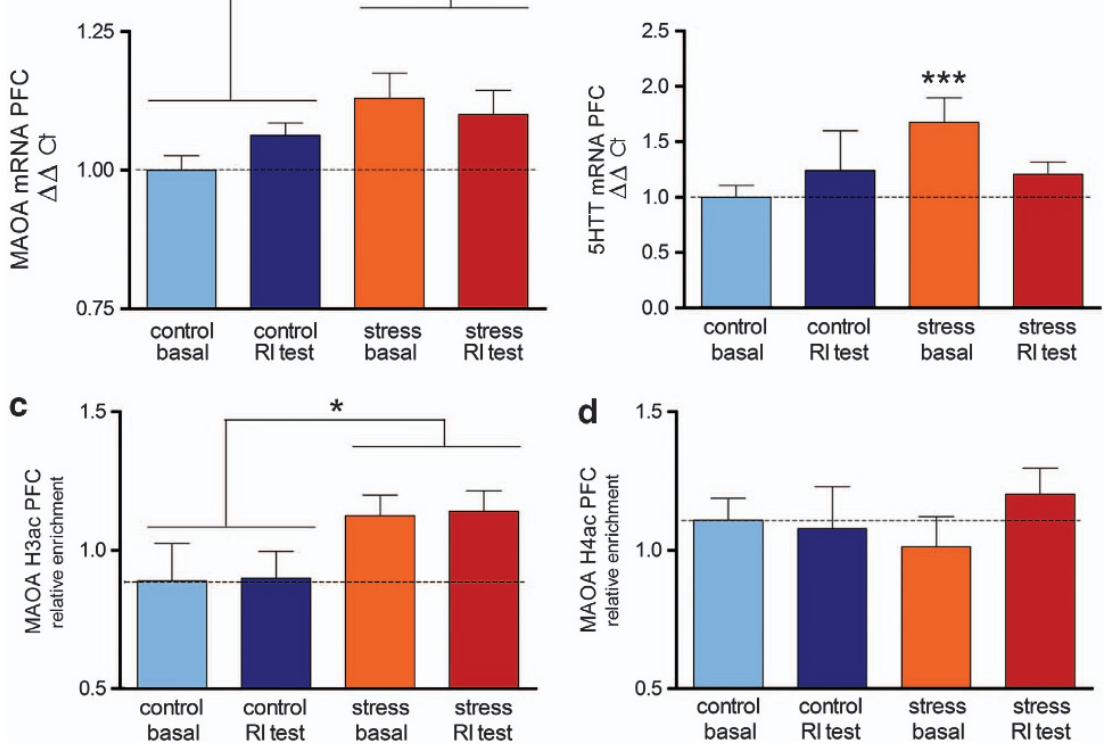

Figure 3 Monoamine oxidase $A(M A O A)$ and 5-HT transporter (5HTT) expression and epigenetic control in prefrontal cortex. Quantitative real-time polymerase chain reaction (RT-PCR) analysis revealed (a) increased levels of MAOA mRNA in the prefrontal cortex (PFC) under both basal conditions and after the resident-intruder test in peripubertally stressed animals (stress effect: $F_{1,38}=5.43, P<0.05$ ), and a (b) significant basal increase in the expression of $5 \mathrm{HTT}$ in the PFC (stress effect: $F_{1,38}=5.2$, $P<0.05$ and interaction between stress and sampling time: $F_{1,38}=6.27, P<0.05$ ). Post hoc comparisons revealed that the $5 \mathrm{HTT}$ mRNA basal levels were different from all of the other groups $(P=0.001)$. Chromatin immunoprecipitation $(\mathrm{ChIP})$ analyses revealed an $(\mathbf{c})$ increase of acetylation of MAOA H3 (stress effect: $\left.F_{1,37}=6.0, P<0.05\right)$, with (d) no changes in MAOA H4 acetylation ( $n=9-10$ per group). ${ }^{*} P<0.05 ;{ }^{* *} P=0.001$.

acetylation, but not for histone 4 acetylation, for the MAOA gene in the PFC during adulthood. No changes for acetylation of these histones were found for 5HTT gene in the PFC during adulthood (Figure $3 c$ and d, Supplementary Figure S9).

\section{Reversibility of peripubertal stress-induced alterations in social behavior by pharmacological treatment with an MAOA inhibitor. The enhanced MAOA gene expression and its associated $\mathrm{H} 3$ acetylation observed in the PFC of peripubertally stressed animals prompted us to perform a pharmacological experiment using the MAOA inhibitor clorgyline. Chronic treatment of adult rats with a low dose of clorgyline (1 mg/kg per day injected subcutaneously daily during 3 weeks; behavioral testing started $24 \mathrm{~h}$ after treatment) reversed the reduced sociability (Figure $4 \mathrm{a}$ ) and the enhanced aggression in the standard Rl's test (Figure 4b) induced by peripubertal stress. On the contrary, control animals chronically treated with clorgyline showed enhanced aggressive behavior (Figure 4b).}

\section{Discussion}

In humans, it is well established that exposure to stress and maltreatment early in life represents a major risk factor for the development of violent behaviors during adulthood; ${ }^{10,42,43}$ however, the underlying neurobiological mechanisms that mediate the effects of stress remain unclear. In this study, we provide behavioral, endocrine, neurobiological, molecular and pharmacological data supporting the validity of a rat model of hyperaggression induced by exposure to peripubertal stress
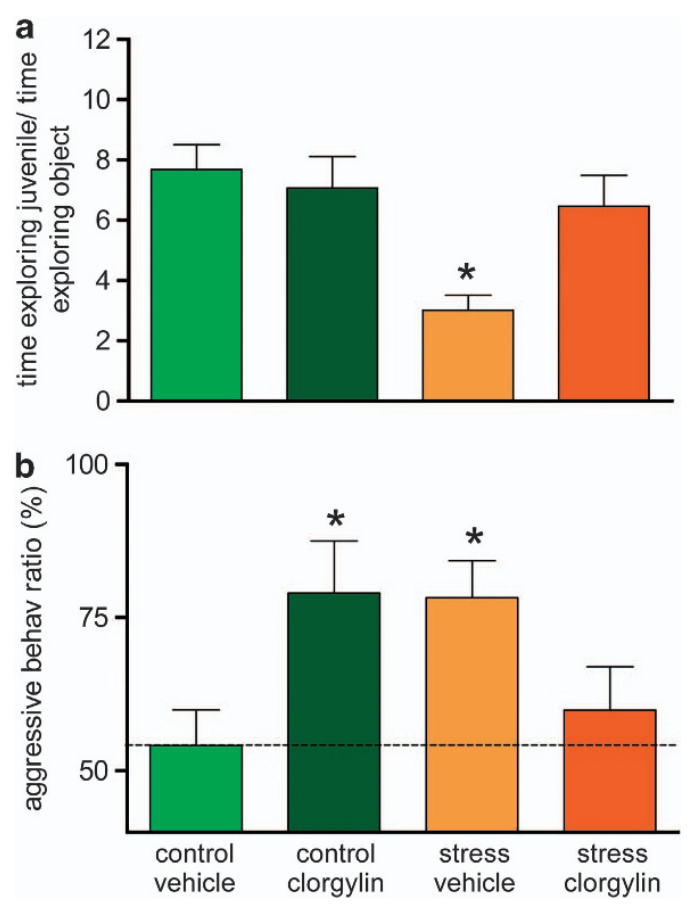

Figure 4 Pharmacological treatment with an monoamine oxidase $A$ (MAOA) inhibitor. (a) The effect of chronic treatment with a low dose of the MAOA inhibitor clorgyline (1 mg/kg per day, 3 weeks; $n=8-10$ per group) in the sociability test (drug $\times$ stress interaction: $F_{1,34}=5.12, P=0.05$ ) and $(\mathbf{b})$ in the resident-intruder test (drug $\times$ stress interaction: $F_{1,30}=9.36, P=0.005$ ) for the ratio of aggressive behaviors (resident $\times 100 /$ total). $\quad{ }^{*} P<0.05$ vs control-vehicle and stress-clorgyline. 
for the investigation of the neural mechanisms that establish a link between early life stress and aggression during adulthood. Our data indicate that the model displays face, construct and predictive validity, and therefore represents a valuable tool for the assessment of potential treatments.

We show that male rats exposed to stressful experiences during the peripubertal period exhibit higher rates of long-term increased aggression. Peripubertally stressed rats are more aggressive than controls in the RI tests and also exhibit an overall pattern of pathological aggression based on the following criteria: ${ }^{4,44}$ (i) they continue attacking even when their opponents display highly submissive postures (that typically in control animals reduce attacks from the resident); (ii) they attack vulnerable body parts; and (iii) they do not discriminate between different types of opponents, attacking unthreatening small and anesthetized males along with larger males. In addition, we have recently shown that the same peripubertal stress protocol leads to increased aggression against females. ${ }^{45}$ Thus, our findings fit with previous human studies showing that children exposed to early life stress show increased risk to develop subsequent aggressive behavior. ${ }^{12,14}$

Also, as previously observed in humans (for a review see Heim et al. ${ }^{46}$ ), peripubertally stressed rats exhibit changes in other behavioral domains, including reduced social tendencies and increased anxiety- and depression-like behaviors. In humans, symptoms of depression and antisocial behaviors frequently co-occur, especially during adolescence and early adulthood, ${ }^{43,47}$ and both have been associated with exposure to adversity early in life. ${ }^{42,43}$ Maternal separation stress during the early postnatal period in rats was previously shown to promote aggression. ${ }^{23}$ Our results extend the stress-sensitivity period for increased aggression to adolescence (that is, peripuberty period) and are in agreement with previous studies that characterized adolescence as a stress-sensitive time-window during which individuals may develop anxietyand depression-like behaviors. ${ }^{48-50}$ Importantly, the lack of behavioral effects observed when the same stress protocol was applied during adulthood highlights peripuberty as a period of special sensitivity to the behavioral programming of aggressive and emotional behaviors. This finding resembles former observations in mice showing that assembling unfamiliar groups at weaning, but not in adulthood or soon after birth, elicits a marked hyperaggression later in life. ${ }^{51,52}$

Although high testosterone and low cortisol levels have been associated independently with social aggression, when both are combined in the same individual aggression seems to be most violent. ${ }^{53}$ Strikingly, the plasma testosterone/ corticosterone ratio measured after the RI test was higher in the peripubertally stressed animals compared with the controls, in agreement with evidence in humans suggesting that this ratio is a hormonal indicator of aggressive behavior. ${ }^{53}$

The pattern of brain activity that we observed in peripubertally stressed rats (that is, hyperactivity in the amygdala under both basal and challenged conditions and hypoactivation of the $\mathrm{MO}$ cortex in response to the social challenge) is in agreement with previous findings of amygdala hyperfunctioning and $\mathrm{MO}$ cortex hypofunctioning in humans with impulsive aggression. ${ }^{54,55}$ Furthermore, our findings are consistent with a large body of data linking amygdala hyperactivity and orbitofrontal cortex dysfunction to increased emotionality, impulsivity and aggression (for reviews, see Coccaro et al. ${ }^{18,56}$ and Davidson et al. $\left.{ }^{56}\right)$. Our data therefore support a model linking dysfunction of the neural circuitry underlying emotional regulation with impulsive aggression, ${ }^{56}$ suggesting that the association between early life adversity and adult aggression involves the disruption of this circuitry. The results of our structural modeling suggest that a deficiency in $\mathrm{MO}$ cortex recruitment in peripubertally stressed animals is linked to high (medial) amygdala activation, which is similar to neuroimaging observations in humans presenting the lowexpression MAOA allelic variant that is associated with an enhanced risk for impulsive-aggressive behavior. ${ }^{16,56}$

There is a large amount of evidence supporting the association between the 5-HT system and aggression and violence. $^{5-7,18}$ We observed increased expression of the MAOA gene in the PFC in peripuberty stress animals under basal conditions and following an $\mathrm{RI}$ test. In contrast, increased basal expression of the 5HTT gene in the same brain region normalized after the social challenge. Overall, these findings are in agreement with reports implicating changes in the 5-HT system in different models of early life stress. ${ }^{3,57}$ Although the finding of enhanced 5HTT gene expression might seem counterintuitive in light of early accounts in the literature proposing enhanced vulnerability to early life stress and psychopathology in association with genetic variants leading to reduced 5 HTT gene expression, ${ }^{58}$ it is important to note that the developmental period when variations in the expression or function of this gene occur seem to be critical. As opposed to constitutive genetic deficiencies present throughout very early development, in our model, peripuberty stress-induced increases in PFC 5HTT expression occur after the major early developmental changes have occurred. In this connection, note the positive mood effects exerted by 5 -HT-specific reuptake inhibitors in adult individuals. Similarly, former simplistic accounts linking 5-HT with aggression have been recently reviewed to account for a more complex picture depicting both low and high 5-HT levels in association with different types of aggression. ${ }^{4}$

PFC function is highly sensitive to changes in the activity of the $5-\mathrm{HT}$ system, ${ }^{59,60}$ and this interaction appears to be compromised in impulsive-aggressive individuals. For example, an increase in glucose metabolism in the PFC observed in normal subjects in response to a 5-HT agonist (fenfluramine) was found to be blunted or entirely absent in patients with aggressive-impulsive personality disorder, ${ }^{61,62}$ a finding that was particularly significant for the $\mathrm{MO}$ cortex. ${ }^{63}$ It has been proposed that the decreased activation of inhibitory regions, such as the prefrontal and $\mathrm{MO}$ regions, in patients with impulsive aggression in response to a serotonergic stimulus contributes to their reduced ability to modulate aggressive impulses. ${ }^{64}$ In this context, our results put forward the increased expression of the MAOA and 5HTT genes in the $\mathrm{PFC}$ as a possible mechanism underlying the blunted $\mathrm{MO}$ cortex response to the $\mathrm{Rl}$ challenge.

In our study, we also observed increased acetylation of histone $\mathrm{H} 3$, but not $\mathrm{H} 4$, at the promoter of the MAOA gene in the PFC of peripubertally stressed rats. This observation is in accordance with their increased expression levels of $M A O A$ after the $\mathrm{Rl}$ challenge, as histone acetylation is known to 
increase the accessibility of genes to the transcription machinery, ${ }^{65}$ and in accordance with a proposed role for histone 3 acetylation, but not $\mathrm{H} 4$, in regulating long-term changes in gene expression. ${ }^{66}$ Our observations on the acetylation of the MAOA gene are consistent with recent work implicating epigenetic modifications in the development of several psychiatric disorders ${ }^{67}$ and add to the mounting evidence that some of the enduring effects of early life stress on behavior and psychopathology are linked to changes in the epigenetic control of particular genes. ${ }^{68-70}$ The majority of the developmental studies performed in rodents have utilized either natural or stress-induced changes in the postnatal maternal care. The findings of these research studies have revealed altered epigenetic control of different genes in specific brain regions in adulthood, including the following: the glucocorticoid receptor in the hippocampus, ${ }^{71}$ which was also found to be affected in human suicide victims exposed to childhood abuse or neglect; ${ }^{72}$ the estrogen receptor $(E R)$ gene in the medial preoptic area, ${ }^{73}$ and the brain-derived neurotrophic factor (BDNF) gene in the PFC, ${ }^{74}$ which was also found to be responsive to stress manipulations during adulthood. ${ }^{75}$ Although, in our study, no changes were observed in the histone acetylation of the 5HTT gene in the PFC, the involvement of other epigenetic mechanisms in the upregulation of 5HTT expression in peripubertally stressed animals cannot be excluded. Several examples in the literature report alterations in DNA methylation for this gene, including recent examples in the lymphoblasts of women who exhibit antisocial behavior induced by child abuse. ${ }^{24}$

Peripubertally stressed animals also showed increased anxiety- and depression-like behaviors. Although the link between anxiety and aggression is still under investigation, ${ }^{76}$ a considerable comorbidity has been established between aggression and depression in animals ${ }^{77,78}$ and in humans, particularly during adolescence and early adulthood. ${ }^{43,47}$ Interestingly, a gene $\times$ environment interaction between early life stress and both 5HTT (for a review, see Vergne and Nemeroff ${ }^{79}$ and Caspi et al. ${ }^{80}$ ) and MAOA (Beach et al. ${ }^{43,81}$ and Cicchetti et al. $^{81}$, but note discrepant findings in Caspi et al. ${ }^{10,82}$ and Eley et al. ${ }^{82}$ ) genes has also been associated with depression. Thus, our findings raise the possibility that a link between early life stress, comorbid aggression and depression-like phenotypes relies on changes in the regulation of serotonergic pathways, and more specifically, changes in the expression levels of the MAOA and 5HTT genes in the PFC. Further studies should address the phenotypic and mechanistic relationships between these different peripubertal stress-induced behavioral manifestations.

Our pharmacological experiment showed that chronic treatment with the MAOA inhibitor clorgyline during adulthood reversed the increased aggression and reduced sociability observed in peripubertally stressed animals. These findings support a role for the observed increase in MAOA expression in the development of these behavioral outcomes and suggest that its targeting can be effective for treatment of the aggressive phenotype. It should be noted that animals were tested 1-3 days after the termination of the pharmacological treatment to avoid immediate confounding effects of the drug on behavior. Moreover, and in agreement with previous findings, 9,83 unstressed animals given the same pharmacological treatment showed increased, as opposed to normalized, social interaction during the RI test, further supporting the specificity of the observed normalizing effects of the MAOA inhibitor on peripuberty stress-induced behavioral changes. Taken together, these results support previously established hypotheses that either MAOA hypoor hyperactivity can contribute to pathological aggression. ${ }^{6}$

In conclusion, we present a novel animal model for pathological aggression induced by peripuberty stress with face, construct and predictive validity. The face validity criterion relates the model with impulsive aggression, as peripubertally stressed animals exhibit heightened attacks against all types of opponents and continue attacking opponents regardless of clear indications of defensive behavior. The construct validity of the model is supported by the hallmark alterations of aggressive-impulsive behaviors in human subjects (that is, changes in the amygdala-MO cortex circuitry, ${ }^{18,19}$ the testosterone/corticosterone ratio ${ }^{53}$ and the serotonergic system ${ }^{41}$ ) that are recapitulated in our rat model. The predictive validity criterion relates to the effectiveness of the MAOA inhibitor pharmacological treatment in mitigating antisocial behaviors, as previously reported in humans. Beyond the characterization and validation of the model, our data highlight the impact of biological factors triggered by juvenile adverse experiences on the emergence of violent behaviors, which should thus be considered a critical complement to the predominant views that emphasize cultural and social learning influences as the mediating mechanisms. Importantly, this animal model of peripuberty stress-induced adult aggression provides a unique tool for investigating the underlying neurobiological mechanisms and for testing and developing new treatment approaches that would otherwise be largely unfeasible in human studies.

\section{Conflict of Interest}

The authors declare no conflict of interests.

Acknowledgements. We thank Angélique Vaucher, Coralie Siegmund, Marjorie Clerc, Aliénor Sonnay and Flora Vajda for excellent technical assistance, Manuel Bueno and Sylvain Lengacher for their advice on the gene expression experiments, Julia Parafita for her advice on 2-deoxy-glucose procedure analysis and David Rotllant for his advice in c-Fos immunohistrochemistry. This work was supported by grants from the Swiss National Science Foundation (310000-120791 and 31003AB-135710; Sinergia CRSIK3-122691; and the NCCR 'The synaptic basis of mental diseases'), Oak Foundation, IBRO-SNSF and Roche Research Foundation, and intramural funding from the EPFL.

1. Jonson-Reid M, Presnall N, Drake B, Fox L, Bierut L, Reich W et al. Effects of child maltreatment and inherited liability on antisocial development: an official records study. J Am Acad Child Adolesc Psychiatry 2010; 49: 321-332; quiz 431

2. Su W, Mrug S, Windle M. Social cognitive and emotional mediators link violence exposure and parental nurturance to adolescent aggression. J Clin Child Adolesc Psychol 2010; 39: 814-824.

3. Veenema AH. Early life stress, the development of aggression and neuroendocrine and neurobiological correlates: what can we learn from animal models? Front Neuroendocrinol 2009; 30: 497-518.

4. de Boer SF, Caramaschi D, Natarajan D, Koolhaas JM. The vicious cycle towards violence: focus on the negative feedback mechanisms of brain serotonin neurotransmission. Front Behav Neurosci 2009; 3: 52.

5. Heinz AJ, Beck A, Meyer-Lindenberg A, Sterzer P, Heinz A. Cognitive and neurobiological mechanisms of alcohol-related aggression. Nat Rev Neurosci 2011; 12: 400-413. 
6. Nelson RJ, Trainor BC. Neural mechanisms of aggression. Nat Rev Neurosci 2007; 8 : 536-546

7. Takahashi A, Quadros IM, de Almeida RM, Miczek KA. Behavioral and pharmacogenetics of aggressive behavior. Curr Top Behav Neurosci 2012

8. Brunner HG, Nelen M, Breakefield XO, Ropers HH, van Oost BA. Abnormal behavio associated with a point mutation in the structural gene for monoamine oxidase A. Science 1993; 262: 578-580

9. Cases O, Seif I, Grimsby J, Gaspar P, Chen K, Pournin S et al. Aggressive behavior and altered amounts of brain serotonin and norepinephrine in mice lacking MAOA. Science 1995; 268: 1763-1766

10. Caspi A, McClay J, Moffitt TE, Mill J, Martin J, Craig IW et al. Role of genotype in the cycle of violence in maltreated children. Science 2002; 297: 851-854.

11. Newman TK, Syagailo YV, Barr CS, Wendland JR, Champoux M, Graessle M et al. Monoamine oxidase A gene promoter variation and rearing experience influences aggressive behavior in rhesus monkeys. Biol Psychiatry 2005; 57: 167-172.

12. Reif A, Rosler M, Freitag CM, Schneider M, Eujen A, Kissling $C$ et al. Nature and nurture predispose to violent behavior: serotonergic genes and adverse childhood environment. Neuropsychopharmacology 2007; 32: 2375-2383.

13. Suomi SJ. Risk, resilience, and gene $\times$ environment interactions in rhesus monkeys. Ann NY Acad Sci 2006; 1094: 52-62.

14. Weder N, Yang BZ, Douglas-Palumberi H, Massey J, Krystal JH, Gelernter J et al. MAOA genotype, maltreatment, and aggressive behavior: the changing impact of genotype at varying levels of trauma. Biol Psychiatry 2009; 65: 417-424.

15. Kim-Cohen J, Caspi A, Taylor A, Williams B, Newcombe R, Craig IW et al. MAOA, maltreatment, and gene-environment interaction predicting children's mental health: new evidence and a meta-analysis. Mol Psychiatry 2006; 11: 903-913.

16. Meyer-Lindenberg A, Buckholtz JW, Kolachana B, R Hariri A, Pezawas L, Blasi G et al. Neural mechanisms of genetic risk for impulsivity and violence in humans. Proc Natl Acad Sci USA 2006; 103: 6269-6274.

17. Pezawas L, Meyer-Lindenberg A, Drabant EM, Verchinski BA, Munoz KE, Kolachana BS et al. 5-HTTLPR polymorphism impacts human cingulate-amygdala interactions: a genetic susceptibility mechanism for depression. Nat Neurosci 2005; 8: 828-834.

18. Coccaro EF, Sripada CS, Yanowitch RN, Phan KL. Corticolimbic function in impulsive aggressive behavior. Biol Psychiatry 2011; 69: 1153-1159.

19. Coccaro EF, McCloskey MS, Fitzgerald DA, Phan KL. Amygdala and orbitofrontal reactivity to social threat in individuals with impulsive aggression. Biol Psychiatry 2007: 62: 168-178.

20. Glenn AL, Raine A. The neurobiology of psychopathy. Psychiatr Clin N Am 2008; 31: 463-475; vii.

21. Lee TM, Chan SC, Raine A. Strong limbic and weak frontal activation to aggressive stimuli in spouse abusers. Mol Psychiatry 2008; 13: 655-656.

22. Kinnally EL, Tarara ER, Mason WA, Mendoza SP, Abel K, Lyons LA et al. Serotonin transporter expression is predicted by early life stress and is associated with disinhibited behavior in infant rhesus macaques. Genes Brain Behav 2010; 9: 45-52.

23. Veenema AH, Blume A, Niederle D, Buwalda B, Neumann ID. Effects of early life stress on adult male aggression and hypothalamic vasopressin and serotonin. Eur J Neurosci 2006; 24: $1711-1720$

24. Beach SR, Brody GH, Todorov AA, Gunter TD, Philibert RA. Methylation at 5HTT mediates the impact of child sex abuse on women's antisocial behavior: an examination of the lowa adoptee sample. Psychosom Med 2011; 73: 83-87.

25. Toledo-Rodriguez M, Sandi C. Stress during adolescence increases novelty seeking and risk-taking behavior in male and female rats. Front Behav Neurosci 2011; 5: 17.

26. Spear LP. The adolescent brain and age-related behavioral manifestations. Neurosci Biobehav Rev 2000; 24: 417-463.

27. Tsoory M, Richter-Levin G. Learning under stress in the adult rat is differentially affected by 'juvenile' or 'adolescent' stress. Int J Neuropsychopharmacol 2006; 9: 713-728.

28. Willner P, Towell A, Sampson D, Sophokleous S, Muscat R. Reduction of sucrose preference by chronic unpredictable mild stress, and its restoration by a tricyclic antidepressant. Psychopharmacology (Berl) 1987; 93: 358-364.

29. Moy SS, Nadler JJ, Perez A, Barbaro RP, Johns JM, Magnuson TR et al. Sociability and preference for social novelty in five inbred strains: an approach to assess autistic-like behavior in mice. Genes Brain Behav 2004; 3: 287-302.

30. Calandreau L, Marquez C, Bisaz R, Fantin M, Sandi C. Differential impact of polysialyltransferase ST8Siall and ST8SialV knockout on social interaction and aggression. Genes Brain Behav 2010; 9: 958-967.

31. Dulawa SC, Holick KA, Gundersen B, Hen R. Effects of chronic fluoxetine in animal models of anxiety and depression. Neuropsychopharmacology 2004; 29: 1321-1330.

32. Pellow S, File SE. Anxiolytic and anxiogenic drug effects on exploratory activity in an elevated plus-maze: a novel test of anxiety in the rat. Pharmacol Biochem Behav 1986; 24 525-529.

33. Cordero MI, Sandi C. Stress amplifies memory for social hierarchy. Front Neurosci 2007; 1 : 175-184

34. Porsolt RD, Bertin A, Jalfre M. Behavioral despair in mice: a primary screening test for antidepressants. Arch Int Pharmacodyn Ther 1977; 229: 327-336

35. Porsolt RD, Brossard G, Hautbois C, Roux S. Rodent models of depression: forced swimming and tail suspension behavioral despair tests in rats and mice. Curr Protoc Neurosci 2001 Chapter 8, Unit 810 A.
36. Marquez C, Nadal R, Armario A. The hypothalamic-pituitary-adrenal and glucose responses to daily repeated immobilisation stress in rats: individual differences. Neuroscience 2004; 123: 601-612.

37. Buckholtz JW, Callicott JH, Kolachana B, Hariri AR, Goldberg TE, Genderson M et al. Genetic variation in MAOA modulates ventromedial prefrontal circuitry mediating individual differences in human personality. Mol Psychiatry 2008; 13: 313-324.

38. Castro JE, Varea E, Marquez C, Cordero MI, Poirier G, Sandi C. Role of the amygdala in antidepressant effects on hippocampal cell proliferation and survival and on depressionlike behavior in the rat. PLoS One 2010; 5: e8618.

39. McIntosh AR, Gonzalez-Lima F. Structural modeling of functional neural pathways mapped with 2-deoxyglucose: effects of acoustic startle habituation on the auditory system. Brain Res 1991; 547: 295-302.

40. Jakobsson J, Cordero Ml, Bisaz R, Groner AC, Busskamp V, Bensadoun JC et al. KAP1mediated epigenetic repression in the forebrain modulates behavioral vulnerability to stress. Neuron 2008; 60: 818-831.

41. Buckholtz JW, Meyer-Lindenberg A. MAOA and the neurogenetic architecture of human aggression. Trends Neurosci 2008; 31: 120-129.

42. Johnson JG, Cohen P, Brown J, Smailes EM, Bernstein DP. Childhood maltreatment increases risk for personality disorders during early adulthood. Arch Gen Psychiatry 1999; 56: $600-606$

43. Beach SR, Brody GH, Gunter TD, Packer H, Wernett P, Philibert RA. Child maltreatment moderates the association of MAOA with symptoms of depression and antisocial personality disorder. J Fam Psychol 2010; 24: 12-20.

44. Haller J, Kruk MR. Normal and abnormal aggression: human disorders and novel laboratory models. Neurosci Biobehav Rev 2006; 30: 292-303.

45. Cordero MI, Poirier GL, Marquez C, Veenit V, Fontana X, Salehi B et al. Evidence for biological roots in the transgenerational transmission of intimate partner violence. Trans Psychiatry 2012; 2: e106.

46. Heim C, Shugart M, Craighead WE, Nemeroff CB. Neurobiological and psychiatric consequences of child abuse and neglect. Dev Psychobiol 2010; 52: 671-690.

47. Patterson GR, Stoolmiller M. Replications of a dual failure model for boys' depressed mood. J Consult Clin Psychol 1991; 59: 491-498.

48. Tsoory M, Cohen H, Richter-Levin G. Juvenile stress induces a predisposition to either anxiety or depressive-like symptoms following stress in adulthood. Eur Neuropsychopharmacol 2007; 17: 245-256.

49. Ilin Y, Richter-Levin G. Enriched environment experience overcomes learning deficits and depressive-like behavior induced by juvenile stress. PLoS One 2009; 4: e4329.

50. McCormick CM, Mathews IZ, Thomas C, Waters P. Investigations of HPA function and the enduring consequences of stressors in adolescence in animal models. Brain Cogn 2010; 72: $73-85$

51. Bartolomucci A, Chirieleison A, Gioiosa L, Ceresini G, Parmigiani S, Palanza P. Age at group formation alters behavior and physiology in male but not female CD-1 mice. Physiol Behav 2004; 82: 425-434.

52. Bartolomucci A, Gioiosa L, Chirieleison A, Ceresini G, Parmigiani S, Palanza P. Cross fostering in mice: behavioral and physiological carry-over effects in adulthood. Genes Brain Behav 2004; 3: 115-122.

53. Terburg D, Morgan B, van Honk J. The testosterone-cortisol ratio: a hormonal marker for proneness to social aggression. Int J Law Psychiatry 2009; 32: 216-223.

54. Raine A, Buchsbaum M, LaCasse L. Brain abnormalities in murderers indicated by positron emission tomography. Biol Psychiatry 1997; 42: 495-508.

55. Raine A, Meloy JR, Bihrle S, Stoddard J, LaCasse L, Buchsbaum MS. Reduced prefrontal and increased subcortical brain functioning assessed using positron emission tomography in predatory and affective murderers. Behav Sci Law 1998; 16: 319-332.

56. Davidson RJ, Putnam KM, Larson CL. Dysfunction in the neural circuitry of emotion regulation-a possible prelude to violence. Science 2000; 289: 591-594.

57. Franklin TB, Linder N, Russig H, Thony B, Mansuy IM. Influence of early stress on social abilities and serotonergic functions across generations in mice. PLOS One 2011; 6: e21842.

58. Uher R, McGuffin $P$. The moderation by the serotonin transporter gene of environmental adversity in the etiology of depression: 2009 update. Mol Psychiatry 2010; 15: 18-22.

59. Mann JJ, Malone KM, Diehl DJ, Perel J, Nichols TE, Mintun MA. Positron emission tomographic imaging of serotonin activation effects on prefrontal cortex in healthy volunteers. J Cereb Blood Flow Metab 1996; 16: 418-426.

60. Puig MV, Celada P, Diaz-Mataix L, Artigas F. In vivo modulation of the activity of pyramidal neurons in the rat medial prefrontal cortex by $5-\mathrm{HT} 2 \mathrm{~A}$ receptors: relationship to thalamocortical afferents. Cereb Cortex 2003; 13: 870-882.

61. Siever LJ, Buchsbaum MS, New AS, Spiegel-Cohen J, Wei T, Hazlett EA et al. $\mathrm{D}, \mathrm{L}-\mathrm{fenfluramine}$ response in impulsive personality disorder assessed with $\left[{ }^{18} \mathrm{~F}\right]$ fluorodeoxyglucose positron emission tomography. Neuropsychopharmacology 1999; 20: 413-423.

62. Soloff PH, Meltzer CC, Greer PJ, Constantine D, Kelly TM. A fenfluramine-activated FDGPET study of borderline personality disorder. Biol Psychiatry 2000; 47: 540-547.

63. Soloff PH, Meltzer CC, Becker C, Greer PJ, Kelly TM, Constantine D. Impulsivity and prefrontal hypometabolism in borderline personality disorder. Psychiatry Res 2003; 123: 153-163.

64. New AS, Hazlett EA, Buchsbaum MS, Goodman M, Reynolds D, Mitropoulou V et al. Blunted prefrontal cortical 18fluorodeoxyglucose positron emission tomography response to meta-chlorophenylpiperazine in impulsive aggression. Arch Gen Psychiatry 2002; 59 : 621-629. 
65. Kuo $\mathrm{MH}$, Allis $\mathrm{CD}$. Roles of histone acetyltransferases and deacetylases in gene regulation. BioEssays 1998; 20: 615-626.

66. Tsankova N, Renthal W, Kumar A, Nestler EJ. Epigenetic regulation in psychiatric disorders. Nat Rev Neurosci 2007; 8: 355-367.

67. Bredy TW, Sun YE, Kobor MS. How the epigenome contributes to the development of psychiatric disorders. Dev Psychobiol 2010; 52: 331-342.

68. Champagne FA, Curley JP. Epigenetic mechanisms mediating the long-term effects of maternal care on development. Neurosci Biobehav Rev 2009; 33: 593-600.

69. McGowan PO, Szyf M. The epigenetics of social adversity in early life: implications for mental health outcomes. Neurobiol Dis 2010; 39: 66-72.

70. Curley JP, Jensen CL, Mashoodh R, Champagne FA. Social influences on neurobiology and behavior: epigenetic effects during development. Psychoneuroendocrinology 2011; 36: 352-371.

71. Weaver IC, Cervoni N, Champagne FA, D'Alessio AC, Sharma S, Seckl JR et al. Epigenetic programming by maternal behavior. Nat Neurosci 2004; 7: 847-854.

72. McGowan PO, Sasaki A, D'Alessio AC, Dymov S, Labonte B, Szyf M et al. Epigenetic regulation of the glucocorticoid receptor in human brain associates with childhood abuse. Nat Neurosci 2009; 12: 342-348.

73. Champagne FA, Weaver IC, Diorio J, Dymov S, Szyf M, Meaney MJ. Maternal care associated with methylation of the estrogen receptor-alpha1b promoter and estrogen receptor-alpha expression in the medial preoptic area of female offspring. Endocrinology 2006; 147: 2909-2915.

74. Roth TL, Lubin FD, Funk AJ, Sweatt JD. Lasting epigenetic influence of early-life adversity on the BDNF gene. Biol Psychiatry 2009; 65: 760-769.

75. Tsankova NM, Berton O, Renthal W, Kumar A, Neve RL, Nestler EJ. Sustained hippocampal chromatin regulation in a mouse model of depression and antidepressant action. Nat Neurosci 2006; 9: 519-525.

76. Neumann ID, Veenema AH, Beiderbeck DI. Aggression and anxiety: social context and neurobiological links. Front Behav Neurosci 2010; 4: 12.
77. Wood GE, Norris EH, Waters E, Stoldt JT, McEwen BS. Chronic immobilization stress alters aspects of emotionality and associative learning in the rat. Behav Neurosci 2008; 122: 282-292.

78. Uchida S, Hara K, Kobayashi A, Fujimoto M, Otsuki K, Yamagata H et al. Impaired hippocampal spinogenesis and neurogenesis and altered affective behavior in mice lacking heat shock factor 1. Proc Natl Acad Sci USA 2011; 108: 1681-1686.

79. Vergne DE, Nemeroff CB. The interaction of serotonin transporter gene polymorphisms and early adverse life events on vulnerability for major depression. Curr Psychiatry Rep 2006; 8: 452-457.

80. Caspi A, Hariri AR, Holmes A, Uher R, Moffitt TE. Genetic sensitivity to the environment: the case of the serotonin transporter gene and its implications for studying complex diseases and traits. Am J Psychiatry 2010; 167: 509-527.

81. Cicchetti D, Rogosch FA, Sturge-Apple ML. Interactions of child maltreatment and serotonin transporter and monoamine oxidase A polymorphisms: depressive symptomatology among adolescents from low socioeconomic status backgrounds. Dev Psychopathol 2007; 19: 1161-1180.

82. Eley TC, Sugden K, Corsico A, Gregory AM, Sham P, McGuffin P et al. Gene-environment interaction analysis of serotonin system markers with adolescent depression. Mol Psychiatry 2004; 9: 908-915.

83. Alia-Klein N, Goldstein RZ, Kriplani A, Logan J, Tomasi D, Williams B et al. Brain monoamine oxidase A activity predicts trait aggression. J Neurosci 2008; 28: 5099-5104.

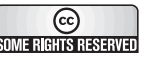

Translational Psychiatry is an open-access journal published by Nature Publishing Group. This work is licensed under the Creative Commons Attribution-NonCommercial-No Derivative Works 3.0 Unported License. To view a copy of this license, visit http://creativecommons.org/licenses/by-nc-nd/3.0/

Supplementary Information accompanies the paper on the Translational Psychiatry website (http://www.nature.com/tp) 